\author{
Hongzhi Lv \\ Third Hospital of Hebei Medical University \\ Xiaolin Zhang \\ Hebei Medical University \\ Juan Wang \\ Third Hospital of Hebei Medical University \\ Zhiyong Hou \\ Third Hospital of Hebei Medical University \\ Haicheng Wang \\ Third Hospital of Hebei Medical University \\ Chao Li \\ Third Hospital of Hebei Medical University \\ Wenjuan Wang \\ Third Hospital of Hebei Medical University \\ Wei Chen \\ Third Hospital of Hebei Medical University \\ Yingze Zhang ( $\sigma$ dryzzhang@126.com ) \\ Third Hospital of Hebei Medical University
}

8 Research Square

Preprints are preliminary reports that have not undergone peer review. They should not be considered conclusive, used to inform clinical practice, or referenced by the media as validated information.

\section{Short-term effects of COVID-19 on risk of traumatic fractures in China: a multi- city study}

\section{Research Article}

Keywords: COVID-19, pandemic, fracture, risk, distributed lag nonlinear model

Posted Date: March 9th, 2021

DOl: https://doi.org/10.21203/rs.3.rs-181106/v1

License: (c) (i) This work is licensed under a Creative Commons Attribution 4.0 International License. Read Full License 


\section{Abstract}

Introduction: Traumatic injury is a leading cause of death and disability worldwide, and fifth most common of in China. Along with the outbreak of COVID-19, strict control measures to restrict people's movement have been conducted in China. Subsequently, the injury mechanisms and pattern of traumatic fractures changed significantly. This study aimed to investigate the associations between COVID-19 and fracture risk, and provide a targeted reference for the world through China's experience.

Methods: This was a retrospective study of a nationally representative sample of COVID-19 prevalence areas using stratified random sampling. The data of traumatic fracture sustaining patients, including age and sex, fractured sites, mechanism of injury, and concurrent fractures in selected hospitals, were collected from 10 January and 10 July, 2020. The epidemiologic characteristics of traumatic fractures and the associations between COVID-19 and fracture risk were explored using the descriptive epidemiological methods and distribution lag nonlinear model.

Results: A total of 67,249 (52.3\% males) patients (average age $49.4 \pm 19.4$ years) with 68,989 fractures were included. The highest proportion of fractures were sustained to the tibia and fibula (14.9\%), followed by the femur (13.6\%), and ulna and radius (12.5\%). Low-energy fractures accounted for $23.3 \%$. With the increase of newly confirmed COVID-19 cases, fracture risk decreased for children, young and middle-aged adults, elderly men, high-energy fracture, and for residents in low and middle-prevalence areas.

Conclusion: Fracture risk decreased sharply in all residents except elderly women, low-energy fractures, and in high-prevalence areas when newly confirmed COVID-19 cases increased in China. Primary (home) prevention measures are emphasized to prevent traumatic fractures during the COVID-19 pandemic.

\section{Background}

The outbreak of coronavirus disease (COVID-19) has swept the world and has officially been declared a global pandemic. ${ }^{1-5}$ By 26 November 2020 , the outbreak of COVID-19 has generated more than 60,864,066 confirmed cases in 208 countries, including 1,429,812 deaths

(https://voice.baidu.com/act/newpneumonia/newpneumonia). Many countries have taken preventive and strict control measures to restrict people's movement, including the wearing of masks, self-isolation at home, traffic control, and community blockade. Although China has suffered from the COVID-19 outbreak since 20 January 2020, the government has taken strict prevention and movement-restricting measures, which have been proven to be very effective to control and wipe out the pandemic. Since March 18, there were no new confirmed cases in China for the first time; all new confirmed cases were imported (https://voice.baidu.com/act/newpneumonia/newpneumonia).

Traumatic injury is one of the leading causes of death and disability worldwide. Injuries also place a huge burden on China, being the fifth most common cause of death, resulting in more deaths than diabetes and infectious diseases. ${ }^{6}$ Injury-related fractures are the primary drain of medical resources. ${ }^{7-8}$ The spread of COVID-19 was associated with the occurrence of traumatic fractures due to changes in lifestyle and psychological state. Several studies have reported that preventive measures such as self-isolation at home, traffic control, and strict access to the community decreased the risk of traumatic fractures. ${ }^{9-10}$ To date, however, the effect of COVID-19 prevalence on traumatic fractures has not been investigated extensively.

It is important to investigate the epidemiology of patients with COVID-19 and identify the risk factors for traumatic fractures. Therefore, the purpose of this study was to evaluate the relationship between traumatic fractures and the spread of COVID-19. We also evaluated whether this relationship changed according to age, sex, site, injury mechanism, and epidemic area of traumatic fractures.

\section{Patients And Methods}

\section{Data sources}

\section{Sampling methods}

This was a retrospective survey. During the main sampling phase, 31 provinces (municipalities or autonomous regions) in mainland China were categorized into three regions (high COVID-19 prevalence, middle COVID-19 prevalence, and low COVID-19 prevalence) according to the cumulative number of confirmed cases per province (http://www.nhc.gov.cn/xcs/yqtb/list_gzbd.shtml). Fourteen provinces and municipalities were calculated with the optimum allocation stratified random sampling survey (three from high-prevalence areas, four from the middle-prevalence areas, and seven from the low-prevalence areas, as shown in the flow chart in Fig 1). Within each targeted province, one or two hospitals were randomly selected. In cases where the hospital manager refused to allow the hospital to participate, an alternative hospital was randomly selected from the list using a modified version of the Kish method. ${ }^{11}$ Finally, 18 hospitals were selected, including the Third Hospital of Hebei Medical University, Beihai People's Hospital, Jingxing County Hospital, People's Hospital of Peking University, Beijing Jishuitan Hospital, The First Affiliated Hospital of Dalian Medical University, The First Affiliated Hospital of Fujian Medical University, Fuzhou No.2 Hospital, Henan Provincial People's Hospital, China-Japan Union Hospital, Hospital of Jilin University, Jiangsu Provincial People's Hospital, Nanfang Hospital Affiliated to Southern Medical University, Affiliated Hospital of Nantong University, Affiliated Hospital of Qingdao University, Shanghai No.6 People Hospital, Tianjin Hospital, Wuhan Union Hospital, and The First Affiliated Hospital of Xinjiang Medical University. Of these, there were 17 tertiary referral hospitals and one secondary referral hospital.

This study was approved by the Institutional Review Board of the Third Hospital of Hebei Medical University in compliance with the Helsinki Declaration and consent were waived due to its retrospective nature.

\section{Inclusion and exclusion criteria}


The inclusion criteria were as follows: (1) definite diagnosis of new-onset fracture; (2) the fracture was sustained between 10 January and 10 July, 2020 . The exclusion criteria were (1) pathologic (metastatic) fracture, (2) secondary fracture of various causes, including poor union, nonunion or readmission, and periprosthetic fracture.

\section{Fracture data collection and groups}

All fractures in the selected hospitals from 10 January to 10 July 2020 were collected through the Picture Archiving and Communication System (PACS) and case reports checking systems. The collected data of interest included demographics (age and sex), the fracture site, the mechanism of injury, and concurrent fractures. All medical charts and radiographs for fracture patients in each participating hospital were evaluated by two local orthopedic surgeons and were addressed by discussion if there was any inconsistency. Based on age, all patients were divided into three groups: children ( $\leq 14$ years), young and middleaged adults (15-64 years), and older patients ( $\geq 65$ years). Subjects were also stratified into the following age groups: $0-4,5-14$, followed by an age group of 10 years, and $\geqq 65$ years.

The fracture sites were recorded as proximal, shaft, and distal fracture for each limb long-bone (humerus, ulna and radius, femur, and tibia and fibula); pelvic and acetabular fractures; scapula; clavicle; patella; spine; hand and wrist; foot and ankle; and other, including sternum, rib, and head fracture. Patients who met the following three criteria were considered to have sustained osteoporotic fracture: (1) occurred in one of the four sites (hip, thoracic and lumbar vertebra, distal radius, and proximal humerus), (2) $\geq 65$ years old, and (3) low-energy injury. ${ }^{12-16}$

The injury mechanism included low-energy and high-energy fractures. A low-energy fracture was defined as a fracture caused by a fall from standing and low height $(<1 \mathrm{~m})$. A high-energy fracture was defined as a fracture caused by a traffic accident, blunt injury, sharp instrument injury, fall from high height, explosive crush injury, and others.

\section{COVID-19 cases}

The daily average COVID-19 cases comes from the National Health Commission of the people's Republic of China platform. The system fulfilled the quality assurance and quality control tasks of the Chinese government. The monitoring station built by the National Health Commission of the people's Republic of China provides COVID-19 data to the system every day to continuously monitor the COVID-19 prevalence throughout China. From January 10 to July 10,2020 , which was the most serious covid-19 epidemic period, there were 183 newly diagnosed cases.bvcxz

\section{Management principle for traumatic fracture in the epidemic of COVID-19}

To ensure that COVID-19 confirmed or suspected cases, or common fractures, were diagnosed in every patient, the recent epidemiological history of the patient was confirmed. At the same time, necessary laboratory and imaging examinations were performed, such as routine blood tests, C-reactive protein, erythrocyte sedimentation rate, lung $\mathrm{CT}$, and viral nucleic acid detection of throat swabs and respiratory tract secretions. All patients with common fractures were treated with first-class protective measures, strict preoperative preparation, intraoperative treatment principles, postoperative nursing and rehabilitation, and follow-up after discharge, so as to formulate a meticulous and operable plan. If COVID-19 was diagnosed or suspected, the isolation measures were immediately implemented and upgraded to level three protection. At the same time, the orthopedics department; infection department; respiratory department; intensive care unit; anesthesiology department; digestive department; and other relevant departments were immediately organized for consultation, and the precise treatment concept of "one person, one policy" was implemented. In principle, patients treatable with a brace were not operated on. For patients requiring surgery, we chose minimally invasive treatment under the premise of ensuring the quality of fracture reduction, so as to decrease the secondary impact of surgical trauma on the immunity of patients. According to the changes in the disease, the treatment plan was adjustable at any time.

\section{Statistical analyses}

Statistical analyses were conducted using the standard statistical software SPSS 23.0 (IBM, Armonk, New York, USA). The Kolmogorov Smirnov test was used to test whether the data conformed to the normal distribution. The t-test of two independent samples was used to compare the age of different genders in accordance with the normal distribution. ANOVA was used to compare age in different epidemic areas.

Statistical analysis was performed using R 2.15.0 (R Foundation for Statistical Computing, Vienna, Austria). We studied the impact of COVID-19 on the number of fracture cases in a distributed lag model. The specific method is to establish a lagging cross-basis matrix of newly diagnosed COVID-19, add the natural cubic spline function of time $a$, and the week variable and holidays as covariates to control the confounding of trend and week effect.

The final distribution lag model is as follows:

Yt quasi-Poisson (fracture cases)

$\log ($ fracture cases $)=a+\eta+n s($ time, $7 *$ year $)+\beta_{3}{ }^{*} D o W+\beta_{4} *$ Holidays

$\eta$ represent the cross-basis function. DoW represents the day of the week. Holidays represent holidays and vacations.

\section{Role of the funding source}

The funding source has no role in study design, conduction, data collection or statistical analysis.

The corresponding author had full access to all the data in the study and had final responsibility for the decision to submit for publication. 


\section{Results}

\section{Descriptive statistics of data}

During the study timeframe, there were a total of 67,249 patients with 68,989 fractures, including 65,715 (95.3\%) patients each having one fracture; 1,377 (20\%) patients with two concurrent fractures; 125 (2\%) patients with three concurrent fractures; $18(0.2 \%)$ patients with four concurrent fractures; 11 ( $0.1 \%)$ patients with five concurrent fractures, and three $(0.4 \%)$ patients with six concurrent fractures. In the Wuhan Union Hospital, there were two fracture patients confirmed with COVID-19 on March 1, and one patient was confirmed with COVID-19 on February 1, including one with femoral neck fracture, one with calcaneal fracture, and one with lumbar fracture.

There were a total of 84,622 newly confirmed COVID-19 patients from January 10 to July 10,2020 . The number of newly confirmed COVID-19 cases was the highest in February (69400) (Fig. 2a), While that of fracture cases was the most in April (479) (Fig. 2b).

\section{Age and gender-specific characteristics}

There were $35,176(52.3 \%)$ male and 32,073 (47.7\%) female patients, with an average age of 49.4 \pm 19.4 years (range, 1-108). The age of males was $43.9 \pm 20.6$ years, significantly younger than that of females $(55.4 \pm 21.0$ years; $t=-71.434, \mathrm{P}<0.01)$. This study collected data on $6,196(9.2 \%)$ children, $42,800(63.6 \%)$ young and middle-aged adults, and 18,235 (27.1\%) elderly patients. The ratio of males to females was $1.9,1.4$, and 0.5 in each age group, respectively. It can be seen from the age-sex pyramid of patient composition that the majority of patients are over 65 years old females (Fig 3 ).

\section{Prevalence area characteristics}

The age in the middle epidemic area was $52.1 \pm 18.9$ years, significantly older than that in the low $(47.0 \pm 22.1)$ and high epidemic areas $(46.4 \pm 23.9, \mathrm{~F}=580.839$, $\mathrm{P}<0.01)$. There are more males than females in the high $(1025 / 760)$ and low $(16528 / 13553)$ epidemic areas, while which was almost the same in the middle (17623/17760) epidemic areas. Adults accounted for the highest proportion in high, middle and low prevalence areas, but the proportion of the elderly in low (Fig 4a) prevalence areas was less than that in high (Fig 4b) and middle prevalence areas (Fig 4c).

\section{Fracture site and injury mechanism characteristics}

Among 68,989 fractures, there were 10,275 tibia and fibula fractures, accounting for $14.9 \%$, followed by femoral fracture $(9,405,13.6 \%)$; ulna and radius $(8,598,12.5 \%)$; others $(8,159,11.8 \%)$; spine $(7,923,11.5 \%)$; humerus $(6,362,9.2 \%)$; foot and ankle $(5,591,8.1 \%)$; hand and wrist $(4,409,6.4 \%)$; clavicle fracture $(2,339,3.4 \%)$; patella $(2,076,3.0 \%)$; pelvis and acetabulum (1,801, 2.6\%); head (1,579, 2.3\%); and scapula (472, 0.7\%) (Fig 5). Among them, single fractures accounted for $97.7 \%(65,712)$ of cases, and multiple fractures accounted for $2.2 \%(1,537)$. There were $46,716(67.7 \%)$ limb fractures and $22,273(32.3 \%)$ trunk fractures.

Among 67,249 patients, the proportion of fractures caused by falling from standing height was $23.3 \%(15,688 / 67,249)$. Other causes included traffic accidents $(44,302,65.9 \%)$, blunt force trauma $(231,0.3 \%)$, crushing injury $(133,0.2 \%)$, others $(428,0.6 \%)$, explosive injury $(115,0.2 \%)$, sharp trauma $(1,571,2.3 \%)$, and falls from heights $(4,781,7.1 \%)$ (Fig 6).

\section{The correlation between variables}

\section{All fracture cases}

Associations between COVID-19 and fracture risk are presented as three-dimensional graphs and two-dimensional contour plots in Fig 7. The varying range of newly confirmed cases is $0-15,152$, and the lag interval is $0-10$ days. Fig. 7A shows that with the increase in the number of newly confirmed COVID-19 cases, the fracture risk first increased and then decreased. As shown in Table 1, on the 0-7 days of lag, with the increase in the number of newly confirmed COVID-19 cases, the fracture risk increased first and then decreased $(\mathrm{P}<0.05)$. On the eighth to tenth day of lag, with the increase in the number of newly confirmed COVID-19 cases, the fracture risk did not change $(P>0.05)$. The contour plot shows a profile of RR of newly confirmed cases with different concentrations and lag days, which makes the relationship between the three more intuitive. Through the "slice" diagram of the RR, it shows that with the new confirmed COVID-19 cases the risk of fracture is gradually reduced (Fig. 7B). Fig 7C provides a two-dimensional exposure lag response correlation. On day zero of lag, with the increase in the number of newly confirmed COVID-19 cases, the fracture risk increased first and then decreased. On the tenth day of lag, with the increase in the number of newly confirmed COVID-19 cases, the fracture risk had no change. When the number of newly confirmed cases was 2,000 , the fracture risk was higher at 0-10 days, reaching the peak on the fifth day $(\mathrm{RR}=1.40,95 \% \mathrm{Cl}: 1.00-1.26)$. When the number of new confirmed cases was 12,000 , the fracture risk was lower at $0-10$ days $(\mathrm{RR}<1)$.

\section{Gender and age}

The fracture risk for males and females decreased with the increase of newly confirmed COVID-19 cases (supplemental figure 1A-B). Supplemental fig 1C-G shows that with the increase of newly confirmed COVID-19 cases, the fracture risk decreased for children, young and middle-aged males and females, and elderly men, while it showed little change for elderly women.

\section{Prevalence area}

Supplementary Fig. 1 H-J shows the impact of COVID-19 on the number of fracture cases in different prevalence areas. With the increase in newly confirmed COVID-19 cases, the fracture risk decreased in the middle-prevalence area and low-prevalence area on the 0-7 days of lag. With the increase in newly confirmed COVID-19 cases, the fracture risk had no change in the high-prevalence area. 
Supplementary fig. 1K-L shows that with the increase of newly confirmed COVID-19 cases the limb and trunk fracture risk decreased. Supplementary fig. $1 \mathrm{~m}$-n shows that with the increase of newly confirmed COVID-19 cases, the single fracture risk decreased, while multiple fractures had no change. Supplementary fig 10-P shows that with the increase of newly confirmed COVID-19 cases, the high-energy fracture risk decreased significantly, while the decrease in lowenergy fracture risk was not obvious.

\section{Discussion}

The present study found direct evidence of the effect of COVID-19 on fracture cases in China. This study compared the data on fractures of 18 hospitals in China within half a year of the COVID-19 outbreak, showing that the relationship between COVID-19 and fracture cases demonstrated a clear S-shaped curve; with the increase of newly confirmed COVID-19 cases, the fracture risk of male, female, children, young men, young women, and elderly men decreased fracture risk in middle and low-prevalence areas, and significantly reduced the risk of limb and trunk fracture. These influences appeared in the $0-7$ days of lag, and no longer existed after the eighth day.

The risk of fracture could be influenced by the pandemic of COVID-19. During the epidemic period, the government took a series of measures to limit travel and reduce the population flow. In many Chinese cities, supermarkets and shopping malls carried less than $5 \%$ of patron volume during the non-epidemic period on January 23, 2020 (https://baijiahao.baidu.com/s?id=1659210676897303602\&wfr=spider\&f or $=p c$ ). Since February 19, almost all residents were isolated in their own homes except for the staff, doctors, and administrators engaged in prevention work, until the number of newly diagnosed patients was zero. Our findings suggest that, with the increase of newly confirmed COVID-19 cases, the fracture risk of male, female, children, young men, young women, and elderly men was decreased. This is because, during the epidemic period, some industries were shut down and production was stopped, the risk of fracture in young and middle-aged people was reduced; the risk of fracture in children was also reduced after school suspension. However, due to the reduction of exercise and the change in sedentary lifestyle during the epidemic period, elderly people who usually stay at home are more likely to sustain a low-energy fracture, especially for elderly women with severe osteoporosis. The risk of fracture did not decrease with the aggravation of the epidemic situation. Therefore, in an epidemic period, we should consider taking targeted fracture prevention and control measures at home, especially for elderly women. These measures can include preventing insufficient lighting and uneven ground in living rooms and washrooms, wearing proper walking aids and antiskid shoes, and arranging furniture. In the same way, for patients with hypertension, diabetes, and other diseases, we should ensure the timely and rational use of medication, and reduce or eliminate the use of psychotropic drugs such as sleeping pills.

In this study, with the increase of newly confirmed COVID-19 cases, the fracture risk decreased in the middle and low-prevalence areas on 0-7 days of lag. However, with the increase in newly confirmed COVID-19 cases, the fracture risk had no change in the high-prevalence area. This indicates that, due to the control measures taken by the government such as traffic control and shutdown, the fracture risk of residents in middle and low-prevalence areas is significantly reduced. The number of patients in the high epidemic area is relatively large, and there is still more personnel flow due to the treatment, drug purchase, and care of family and friends. On the other hand, it also shows that control of personnel flow in high epidemic areas is not strict enough.

In this study, with the increase in the epidemic situation, the single, limb, and trunk fractures decreased obviously, while low-energy fractures did not decrease, accounting for $23.3 \%$ of all injury mechanisms. This is worthy of attention. Abundant low-energy fractures will not only increase the consumption of scarce medical resources, but also lead to disability, reduce the quality of life of patients, and even cause death. ${ }^{17-19}$ Long-term medical care caused by fractures will increase the chance of COVID-19 infection in hospitals. ${ }^{20-23}$ There is also increased evidence indicating that the incidence and mortality rates of elderly patients with COVID-19 are very high. ${ }^{24-26}$ In addition, in the context of COVID-19, less physical labor, a sedentary lifestyle, panic, and depressed mental state increase the risk of low-energy fractures such as falls and slips. ${ }^{27-28}$ Therefore, attention should be paid to the prevention of low-energy fracture in the epidemic period of COVID-19. To avoid the occurrence of low-energy fractures, anti-osteoporosis treatment should be actively undertaken, and calcium agents and active vitamin D3 should be timeously supplemented to promote the absorption of calcium. ${ }^{29-31}$ We should simultaneously guide people on healthy home-based sports activities as well as the correct self-regulation of emotion and psychological state.

This study has several limitations. First, this study is a retrospective design, which inevitably leads to recall bias. However, the data were collected through the PACS and the case report examination systems. The main information is demographic (age and gender), fracture site, injury mechanism, and other basic information, so the recall bias of this study is very small. Second, the number of clinical diagnosis cases was included in the number of confirmed cases according to the novel coronavirus infection diagnosis and treatment plan (5th trial version) (http://www.gov.cn/zhengce/zhengceku/2020-

02/05/content_5474791.htm) on February 12, 2020. This led to a sharp increase in the number of patients on that day, which affected the overall flow of the model. Third, hospitals rather than individuals were randomly selected using the sampling method, as directly selecting individuals randomly in each administrative village or neighborhood community using this method would not have been practical in China.

\section{Declarations}

\section{Patient and public involvement}

The study was approved by the Institutional Review Board of the Third Hospital of Hebei Medical University. This study was a retrospective review of hospital records. Data entry and analysis do not display or use patients' personal identification (ID) information. Therefore, the requirement for informed consents from patients was waived.

\section{Author Contributors}


YZ conceived the idea for the study and managed the project. YZ, HL, XZ, JW, ZH, WC designed the study. YZ, HL, XZ, JW, ZH, WC, HW, CL, WW conducted the survey across China and collected the data. $Y Z, H L, X Z$, WC performed the statistical analyses and wrote the statistical analysis plan. $\mathrm{HL}$ and $\mathrm{XZ}$ wrote the manuscript. JW, ZH and WC prepared the figures and tables. YZ, HL, XZ, JW, ZH, WC revised the manuscript. All authors interpreted the data and contributed to preparation of the manuscript. All authors have approved the submitted version. $\mathrm{HL}$ and $\mathrm{XZ}$ contributed equally.

\section{Declaration of interests}

We declare no competing interests. All authors have read and contributed to the submitted manuscript and have no conflict of interest to declare. This study was approved by the Institutional Review Board of the Third Hospital of Hebei Medical University and registered on the Chinese Clinical Trial Registry (Registration number: ChiCTR-EPR-15005878).

\section{Funding}

This study was supported by the Hebei Province Medical Science Special Major Projects Research Fund. The funding source has no role in study design, conduction, data collection or statistical analysis.

\section{ORCID iDs}

Wei Chen http://orcid.org/0000-0001-5451-6430

Yingze Zhang https://orcid.org/0000-0001-8042-6105

\section{References}

1. Li, Q. et al. Early transmission dynamics in Wuhan, China, of novel coronavirus-infected pneumonia. N Engl J Med. 382, 1199-1207 https://doi.org/10.1056/NEJMoa2001316 (2020).

2. Chen, N. et al. Epidemiological and clinical characteristics of 99 cases of 2019 novel coronavirus pneumonia in Wuhan. China: a descriptive study. Lancet. 20 (20), 30211-30217 (2020).

3. Wang, C., Horby, P. W., Hayden, F. G. \& Gao, G. F. A novel coronavirus outbreak of global health concern. Lancet. 20 (20), 30185-30189 https://doi.org/10.1016/S0140- (2020).

4. Holshue, M. L. et al. First case of 2019 novel coronavirus in the United States. N Engl J Med. 382, 929-936 https://doi.org/10.1056/NEJMoa2001191 (2020).

5. Wang, D. et al. Clinical characteristics of 138 hospitalization patients with 2019 novel coronavirus-infected pneumonia in Wuhan.JAMA2020:1585. doi: 10.1001/jama.2020.1585.

6. Center for Health Statistics and Information, the Ministry of Health of the People's Republic of China. China health statistics annual 2013. 2013. http://www.nhfpc.gov.cn/htmlfiles/zwgkzt/ptjnj/ year2013/index2013.html (accessed Aug 31, 2015).

7. Boonen, S. et al. Fracture risk and zoledronic acid therapy in men with osteoporosis. N Engl J Med. 367, 1714-1723 (2012).

8. Donaldson, L. J., Reckless, I. P., Scholes, S., Mindell, J. S. \& Shelton, N. J. The epidemiology of fractures in England. J Epidemiol Commun Health. 62, 174180 (2008).

9. Lv, H. et al. Epidemiologic characteristics of traumatic fractures during the outbreak of coronavirus disease 2019 (COVID-19) in China: A retrospective \& comparative multi-center study. Injury. 51, 1698-1704 (2020).

10. Zhu, Y. et al. Epidemiologic characteristics of traumatic fractures in elderly patients during the outbreak of coronavirus disease 2019 in China. Int Orthop. 44, 1565-1570 (2020).

11. Reich, J., Yates, W. \& Woolson, R. Kish method for mail survey respondent selection. Am J Public Health. 76 (2), 206 https://doi.org/10.2105/AJPH.76.2.206 (1986).

12. Marsh, D. \& Palm, H. Rising to the challenge of fragility fractures. Injury. 49, 1392 https://doi.org/10.1016/j.injury.2018.06.029 (2018).

13. Fernandez, M. A. \& Costa, M. L. Clinical research in fragility fractures. Injury. 49, 1473-1476 https://doi.org/10.1016/j.injury.2018.06.035 (2018).

14. Cosman, F. et al. Clinician's guide to prevention and treatment of osteoporosis. Osteoporos Int. 25, 2359-2381 https://doi.org/10.1007/s00198-014-27942 (2014).

15. Sale, J. E., Beaton, D. \& Bogoch, E. Secondary prevention after an Osteoporosis-Related fracture an overview. Clin Geriatr Med. 30, 317-332 https://doi.org/10.1016/j.cger.2014.01.009 (2014).

16. Gosch, M. et al. Surgeons save bones: an algorithm for orthopedic surgeons managing secondary fracture prevention. Arch Orthop Trauma Surg. 133, 1101-1108 https://doi.org/10.1007/s00402-013-1774-x (2013).

17. Tang, P. F. et al. Expert consensus on management principles of orthopedic emergency in the epidemic of coronavirus disease 2019. Chin Med J (Engl). 133, 1096-1098 (2020).

18. Make, S. T. E. A. D. I. \& Part of Your Medical Practice STEADI-older adult fall Prevention CDC Injury Center. (online). [EB/OL]. [2019-9-26]. https://www.cdc.gov/- steadi/Accessed April 15, 2017.

19. Panel on Prevention of Falls in Older Persons AGS \& British Geriatrics, S. Summary of the Updated American Geriatrics Society/British Geriatrics Society clinical practice guideline for prevention of falls in older persons. J Am Geriatr Soc. 59, 148-157 (2011). 
20. Lv, H. et al. Epidemiologic characteristics of traumatic fractures during the outbreak of coronavirus disease 2019 (COVID-19) in China: A retrospective \& comparative multi-center study. Injury. 51, 1698-1704 (2020).

21. Johansen, A., Grose, C. \& Havelock, W. Hip fractures in the winterUsing the National Hip Fracture Database to examine seasonal va riation in incidence and mortality. Injury. 088 (2020). 10.1016/j.i njury.2020.02.088

22. Cano, J. R. et al. Is the bone tissue of the femoral neck de mineralised in patients with hip fracture? Injury. 013 https://doi.org/10.1016/j.injury.2020.02.013 (2020).

23. Van Voorden, T. A. J. et al. Effect of the Dutch hip fracture audit implementation on mortality, length of hospital stay and time until surgery in elderly hip fracture patients; a multi-center cohort study. Injury. 084 https://doi.org/10.1016/j.injury.2020.02.084 (2020).

24. Yu, F. \& Xia, W. The epidemiology of osteoporosis, associated fragility fractures, and management gap in China. Arch Osteoporos. 14 (1), 32 (2019).

25. Center, J. R., Nguyen, T. V., Schneider, D., Sambrook, P. N. \& Eisman, J. A. Mortality after all major types of osteoporotic fracture in men and women: an observational study. Lancet. 353, 878-872 https://doi.org/10.1016/S0140-6736(98)09075-8 (1999).

26. Cummings, S. R. \& Melton, L. J. Epidemiology and outcomes of osteoporotic fractures. Lancet. 359, 1761-1767 https://doi.org/10.1016/S01406736(02)08657-9 (2002).

27. Bliuc, D. et al. Mortality risk associated with low-trauma osteoporotic fracture and subsequent fracture in men and women. JAMA. 301, 513-521 https://doi.org/10.1001/jama.2009.50 (2009).

28. Borgstrom, F. et al. Costs and quality of life associated with osteoporosis-related fractures in Sweden. Osteoporos Int. 17, 637-650 https://doi.org/10.1007/s00198-005-0015-8 (2006).

29. Rothan, H. A. \& Byrareddy, S. N. The epidemiology and pathogenesis of coronavirus disease (COVID-19) outbreak. J Autoimmun. 102433 https://doi.org/10.1016/j.jaut.2020.102433 (2020).

30. Guo, Y. R. et al. The origin, transmission and clinical therapies on coronavirus disease 2019 (COVID-19) outbreak-an update on the status. Mil Med Res. 7, 11 https://doi.org/10.1186/s40779-020-00240-0 (2020).

31. Singhal, T. A Review of Coronavirus Disease-2019 (COVID-19). Indian J Pediatr. 87, 281-286 https://doi.org/10.1007/s12098-020-03263-6 (2020).

32. Westbury, L. D. et al. Long-term rates of change in musculoskeletal aging and body composition: findings from the Health, Aging and Body Composition Study. Calcif Tissue Int. 3, 32125471 https://doi.org/10.1007/s00223-020-00679-2 (2020).

33. Zhang, Q., Cai, W., Wang, G. \& Shen, X. Prevalence and contributing factors of osteoporosis in the elderly over 70 years old: an epidemiological study of several community health centers in Shanghai. Ann Palliat Med. 1-8 https://doi.org/10.21037/apm.2020.02.09 (2020).

34. Wang, Y. K. et al. Effects of teriparatide versus alendronate for treatment of postmenopausal osteoporosis: a meta-analysis of randomized controlled trials. Medicine. 96, e6970 https://doi.org/10.1097/MD.0000000000006970 (2017).

35. Stewart, G. A. \& Reddy, S. Clinical evaluation of cost efficacy of drugs for treatment of osteoporosis: A meta-analysis. Endocr Pract. 23, $841-856$ https://doi.org/10.4158/EP161678.RA (2017).

36. Hak, D. J. The biology of fracture healing in osteoporosis and in the presence of anti-osteoporotic drugs. Injury. 49, 1461-1465 https://doi.org/10.1016/j.injury.2018.04.016 (2018).

\section{Table}

Table 1. Effects of new confirmed COVID-19 on traumatic fractures after a 0-10 day lag [RR(95\%CI)] 


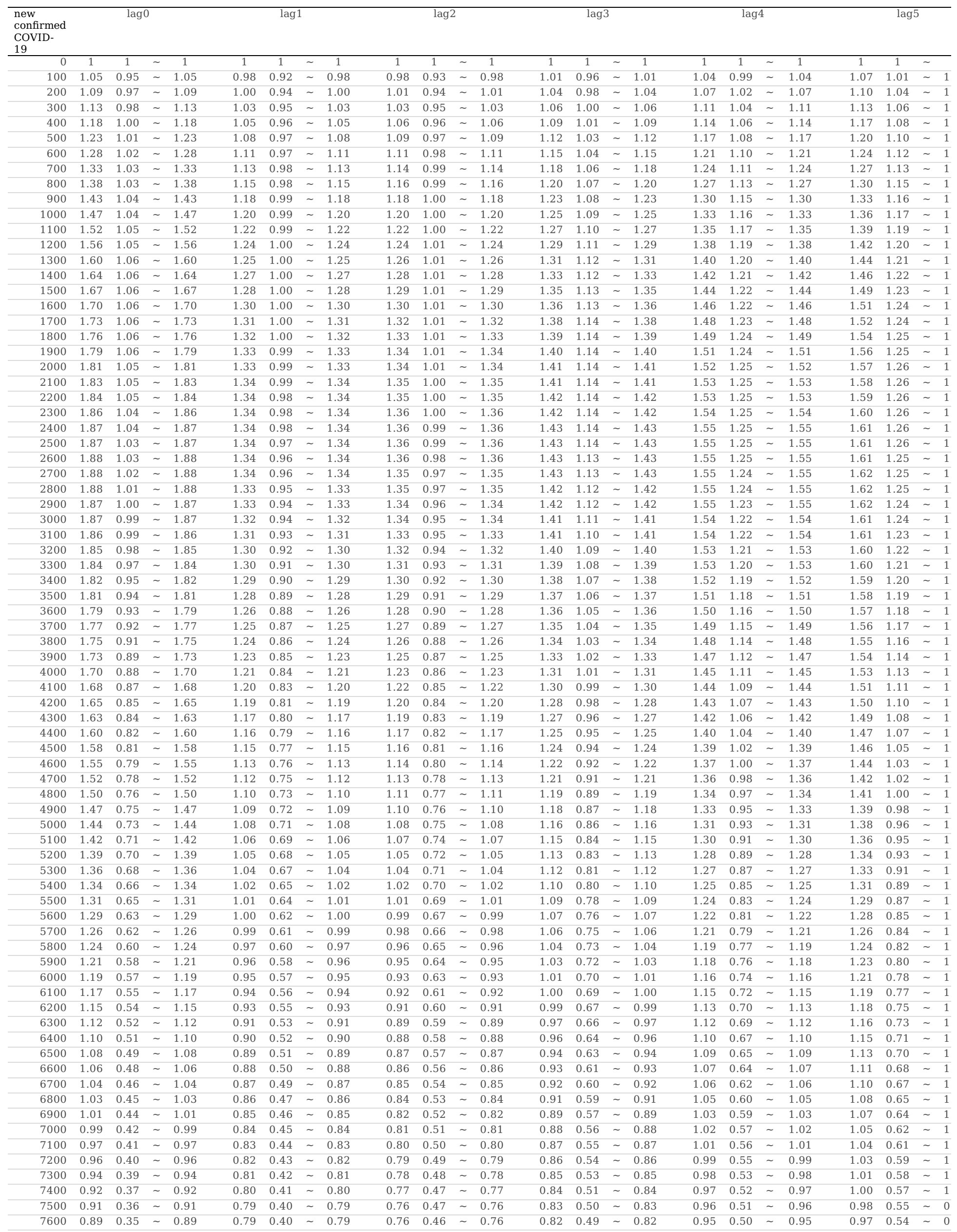




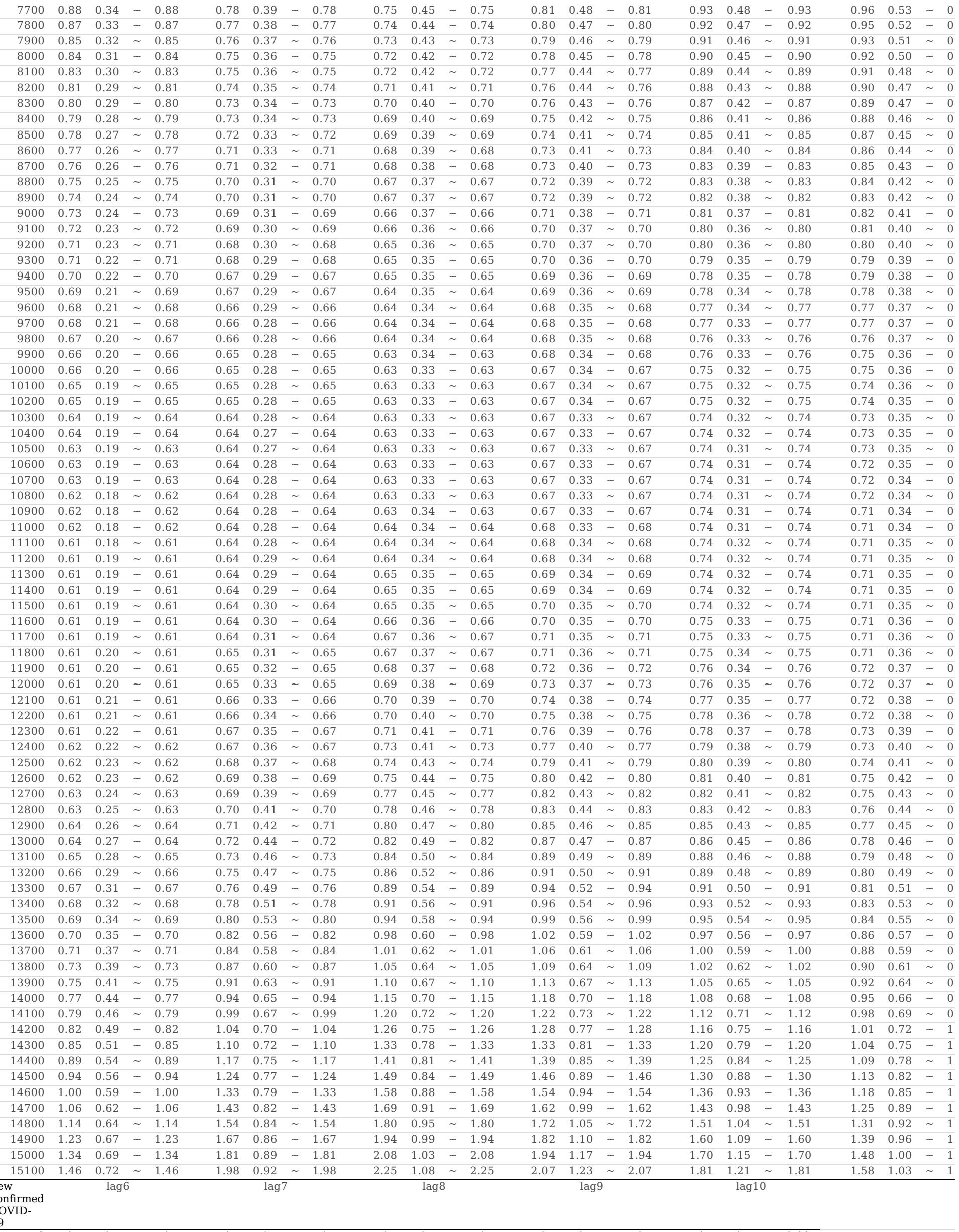

$100 \quad 1.07 \quad 1.02 \sim 1.07 \quad 1.051 .00 \sim 1.05 \quad 1.03 \quad 0.97 \sim 1.03 \quad 1.00 \quad 0.95 \sim 1.00 \quad 1.01 \quad 0.92 \sim 1.01$ 


\begin{tabular}{|c|c|c|c|c|c|c|c|c|c|c|c|c|c|c|c|c|c|c|c|c|}
\hline 200 & 1.10 & 1.04 & $\sim$ & 1.10 & 1.07 & 1.01 & $\sim$ & 1.07 & 1.04 & 0.97 & $\sim$ & 1.04 & 1.00 & 0.95 & $\sim$ & 1.00 & 1.03 & 0.93 & $\sim$ & 1.03 \\
\hline 300 & 1.12 & 1.06 & $\sim$ & 1.12 & 1.09 & 1.02 & $\sim$ & 1.09 & 1.05 & 0.97 & $\sim$ & 1.05 & 1.01 & 0.94 & $\sim$ & 1.01 & 1.04 & 0.93 & $\sim$ & 1.04 \\
\hline 400 & 1.15 & 1.07 & $\sim$ & 1.15 & 1.11 & 1.03 & $\sim$ & 1.11 & 1.06 & 0.97 & $\sim$ & 1.06 & 1.02 & 0.94 & $\sim$ & 1.02 & 1.06 & 0.93 & $\sim$ & 1.06 \\
\hline 500 & 1.18 & 1.09 & $\sim$ & 1.18 & 1.13 & 1.04 & $\sim$ & 1.13 & 1.07 & 0.96 & $\sim$ & 1.07 & 1.02 & 0.93 & $\sim$ & 1.02 & 1.08 & 0.93 & $\sim$ & 1.08 \\
\hline 600 & 1.20 & 1.10 & $\sim$ & 1.20 & 1.14 & 1.04 & $\sim$ & 1.14 & 1.09 & 0.96 & $\sim$ & 1.09 & 1.03 & 0.93 & $\sim$ & 1.03 & 1.10 & 0.93 & $\sim$ & 1.10 \\
\hline 700 & 1.23 & 1.11 & $\sim$ & 1.23 & 1.16 & 1.05 & $\sim$ & 1.16 & 1.10 & 0.95 & $\sim$ & 1.10 & 1.03 & 0.92 & $\sim$ & 1.03 & 1.11 & 0.93 & $\sim$ & 1.11 \\
\hline 800 & 1.26 & 1.13 & $\sim$ & 1.26 & 1.18 & 1.05 & $\sim$ & 1.18 & 1.10 & 0.95 & $\sim$ & 1.10 & 1.04 & 0.92 & $\sim$ & 1.04 & 1.13 & 0.92 & $\sim$ & 1.13 \\
\hline 900 & 1.28 & 1.14 & $\sim$ & 1.28 & 1.19 & 1.05 & $\sim$ & 1.19 & 1.11 & 0.95 & $\sim$ & 1.11 & 1.04 & 0.91 & $\sim$ & 1.04 & 1.15 & 0.92 & $\sim$ & 1.15 \\
\hline 1000 & 1.30 & 1.15 & $\sim$ & 1.30 & 1.20 & 1.06 & $\sim$ & 1.20 & 1.12 & 0.94 & $\sim$ & 1.12 & 1.05 & 0.91 & $\sim$ & 1.05 & 1.16 & 0.92 & $\sim$ & 1.16 \\
\hline 1100 & 1.32 & 1.16 & $\sim$ & 1.32 & 1.22 & 1.06 & $\sim$ & 1.22 & 1.13 & 0.94 & $\sim$ & 1.13 & 1.05 & 0.90 & $\sim$ & 1.05 & 1.18 & 0.92 & $\sim$ & 1.18 \\
\hline 1200 & 1.35 & 1.16 & $\sim$ & 1.35 & 1.23 & 1.06 & $\sim$ & 1.23 & 1.14 & 0.93 & $\sim$ & 1.14 & 1.05 & 0.90 & $\sim$ & 1.05 & 1.19 & 0.91 & $\sim$ & 1.19 \\
\hline 1300 & 1.36 & 1.17 & $\sim$ & 1.36 & 1.24 & 1.07 & $\sim$ & 1.24 & 1.14 & 0.93 & $\sim$ & 1.14 & 1.05 & 0.89 & $\sim$ & 1.05 & 1.20 & 0.91 & $\sim$ & 1.20 \\
\hline 1400 & 1.38 & 1.18 & $\sim$ & 1.38 & 1.25 & 1.07 & $\sim$ & 1.25 & 1.15 & 0.93 & $\sim$ & 1.15 & 1.06 & 0.89 & $\sim$ & 1.06 & 1.22 & 0.91 & $\sim$ & 1.22 \\
\hline 1500 & 1.40 & 1.18 & $\sim$ & 1.40 & 1.26 & 1.07 & $\sim$ & 1.26 & 1.15 & 0.92 & $\sim$ & 1.15 & 1.06 & 0.88 & $\sim$ & 1.06 & 1.23 & 0.90 & $\sim$ & 1.23 \\
\hline 1600 & 1.42 & 1.19 & $\sim$ & 1.42 & 1.27 & 1.07 & $\sim$ & 1.27 & 1.15 & 0.92 & $\sim$ & 1.15 & 1.06 & 0.88 & $\sim$ & 1.06 & 1.24 & 0.90 & $\sim$ & 1.24 \\
\hline 1700 & 1.43 & 1.19 & $\sim$ & 1.43 & 1.28 & 1.07 & $\sim$ & 1.28 & 1.16 & 0.92 & $\sim$ & 1.16 & 1.06 & 0.87 & $\sim$ & 1.06 & 1.25 & 0.90 & $\sim$ & 1.25 \\
\hline 1800 & 1.44 & 1.20 & $\sim$ & 1.44 & 1.28 & 1.07 & $\sim$ & 1.28 & 1.16 & 0.91 & $\sim$ & 1.16 & 1.06 & 0.87 & $\sim$ & 1.06 & 1.26 & 0.89 & $\sim$ & 1.26 \\
\hline 1900 & 1.45 & 1.20 & $\sim$ & 1.45 & 1.29 & 1.07 & $\sim$ & 1.29 & 1.16 & 0.91 & $\sim$ & 1.16 & 1.06 & 0.87 & $\sim$ & 1.06 & 1.27 & 0.89 & $\sim$ & 1.27 \\
\hline 2000 & 1.46 & 1.20 & $\sim$ & 1.46 & 1.29 & 1.07 & $\sim$ & 1.29 & 1.16 & 0.91 & $\sim$ & 1.16 & 1.06 & 0.86 & $\sim$ & 1.06 & 1.27 & 0.89 & $\sim$ & 1.27 \\
\hline 2100 & 1.47 & 1.20 & $\sim$ & 1.47 & 1.30 & 1.07 & $\sim$ & 1.30 & 1.16 & 0.90 & $\sim$ & 1.16 & 1.06 & 0.86 & $\sim$ & 1.06 & 1.28 & 0.88 & $\sim$ & 1.28 \\
\hline 2200 & 1.48 & 1.20 & $\sim$ & 1.48 & 1.30 & 1.07 & $\sim$ & 1.30 & 1.16 & 0.90 & $\sim$ & 1.16 & 1.06 & 0.85 & $\sim$ & 1.06 & 1.28 & 0.88 & $\sim$ & 1.28 \\
\hline 2300 & 1.49 & 1.20 & $\sim$ & 1.49 & 1.30 & 1.07 & $\sim$ & 1.30 & 1.16 & 0.90 & $\sim$ & 1.16 & 1.06 & 0.85 & $\sim$ & 1.06 & 1.29 & 0.87 & $\sim$ & 1.29 \\
\hline 2400 & 1.49 & 1.20 & $\sim$ & 1.49 & 1.30 & 1.07 & $\sim$ & 1.30 & 1.16 & 0.89 & $\sim$ & 1.16 & 1.06 & 0.84 & $\sim$ & 1.06 & 1.29 & 0.87 & $\sim$ & 1.29 \\
\hline 2500 & 1.49 & 1.20 & $\sim$ & 1.49 & 1.30 & 1.06 & $\sim$ & 1.30 & 1.16 & 0.89 & $\sim$ & 1.16 & 1.05 & 0.84 & $\sim$ & 1.05 & 1.29 & 0.86 & $\sim$ & 1.29 \\
\hline 2600 & 1.50 & 1.20 & $\sim$ & 1.50 & 1.30 & 1.06 & $\sim$ & 1.30 & 1.16 & 0.89 & $\sim$ & 1.16 & 1.05 & 0.84 & $\sim$ & 1.05 & 1.30 & 0.86 & $\sim$ & 1.30 \\
\hline 2700 & 1.50 & 1.19 & $\sim$ & 1.50 & 1.30 & 1.06 & $\sim$ & 1.30 & 1.16 & 0.88 & $\sim$ & 1.16 & 1.05 & 0.83 & $\sim$ & 1.05 & 1.30 & 0.86 & $\sim$ & 1.30 \\
\hline 2800 & 1.50 & 1.19 & $\sim$ & 1.50 & 1.30 & 1.05 & $\sim$ & 1.30 & 1.16 & 0.88 & $\sim$ & 1.16 & 1.05 & 0.83 & $\sim$ & 1.05 & 1.30 & 0.85 & $\sim$ & 1.30 \\
\hline 2900 & 1.50 & 1.18 & $\sim$ & 1.50 & 1.30 & 1.05 & $\sim$ & 1.30 & 1.15 & 0.87 & $\sim$ & 1.15 & 1.05 & 0.82 & $\sim$ & 1.05 & 1.30 & 0.85 & $\sim$ & 1.30 \\
\hline 3000 & 1.49 & 1.18 & $\sim$ & 1.49 & 1.29 & 1.04 & $\sim$ & 1.29 & 1.15 & 0.87 & $\sim$ & 1.15 & 1.05 & 0.81 & $\sim$ & 1.05 & 1.30 & 0.84 & $\sim$ & 1.30 \\
\hline 3100 & 1.49 & 1.17 & $\sim$ & 1.49 & 1.29 & 1.04 & $\sim$ & 1.29 & 1.15 & 0.86 & $\sim$ & 1.15 & 1.05 & 0.81 & $\sim$ & 1.05 & 1.30 & 0.84 & $\sim$ & 1.30 \\
\hline 3200 & 1.48 & 1.17 & $\sim$ & 1.48 & 1.29 & 1.03 & $\sim$ & 1.29 & 1.15 & 0.86 & $\sim$ & 1.15 & 1.05 & 0.80 & $\sim$ & 1.05 & 1.29 & 0.83 & $\sim$ & 1.29 \\
\hline 3300 & 1.48 & 1.16 & $\sim$ & 1.48 & 1.28 & 1.03 & $\sim$ & 1.28 & 1.15 & 0.85 & $\sim$ & 1.15 & 1.05 & 0.80 & $\sim$ & 1.05 & 1.29 & 0.83 & $\sim$ & 1.29 \\
\hline 3400 & 1.47 & 1.15 & $\sim$ & 1.47 & 1.28 & 1.02 & $\sim$ & 1.28 & 1.14 & 0.84 & $\sim$ & 1.14 & 1.05 & 0.79 & $\sim$ & 1.05 & 1.29 & 0.82 & $\sim$ & 1.29 \\
\hline 3500 & 1.46 & 1.14 & $\sim$ & 1.46 & 1.27 & 1.01 & $\sim$ & 1.27 & 1.14 & 0.84 & $\sim$ & 1.14 & 1.05 & 0.78 & $\sim$ & 1.05 & 1.29 & 0.81 & $\sim$ & 1.29 \\
\hline 3600 & 1.46 & 1.13 & $\sim$ & 1.46 & 1.27 & 1.01 & $\sim$ & 1.27 & 1.14 & 0.83 & $\sim$ & 1.14 & 1.05 & 0.77 & $\sim$ & 1.05 & 1.28 & 0.81 & $\sim$ & 1.28 \\
\hline 3700 & 1.45 & 1.13 & $\sim$ & 1.45 & 1.26 & 1.00 & $\sim$ & 1.26 & 1.14 & 0.82 & $\sim$ & 1.14 & 1.05 & 0.77 & $\sim$ & 1.05 & 1.28 & 0.80 & $\sim$ & 1.28 \\
\hline 3800 & 1.44 & 1.12 & $\sim$ & 1.44 & 1.26 & 0.99 & $\sim$ & 1.26 & 1.14 & 0.81 & $\sim$ & 1.14 & 1.05 & 0.76 & $\sim$ & 1.05 & 1.27 & 0.80 & $\sim$ & 1.27 \\
\hline 3900 & 1.43 & 1.11 & $\sim$ & 1.43 & 1.25 & 0.98 & $\sim$ & 1.25 & 1.14 & 0.81 & $\sim$ & 1.14 & 1.05 & 0.75 & $\sim$ & 1.05 & 1.27 & 0.79 & $\sim$ & 1.27 \\
\hline 4000 & 1.41 & 1.09 & $\sim$ & 1.41 & 1.24 & 0.97 & $\sim$ & 1.24 & 1.14 & 0.80 & $\sim$ & 1.14 & 1.05 & 0.74 & $\sim$ & 1.05 & 1.27 & 0.78 & $\sim$ & 1.27 \\
\hline 4100 & 1.40 & 1.08 & $\sim$ & 1.40 & 1.24 & 0.96 & $\sim$ & 1.24 & 1.14 & 0.79 & $\sim$ & 1.14 & 1.05 & 0.73 & $\sim$ & 1.05 & 1.26 & 0.78 & $\sim$ & 1.26 \\
\hline 4200 & 1.39 & 1.07 & $\sim$ & 1.39 & 1.23 & 0.95 & $\sim$ & 1.23 & 1.14 & 0.78 & $\sim$ & 1.14 & 1.06 & 0.73 & $\sim$ & 1.06 & 1.26 & 0.77 & $\sim$ & 1.26 \\
\hline 4300 & 1.38 & 1.06 & $\sim$ & 1.38 & 1.22 & 0.94 & $\sim$ & 1.22 & 1.14 & 0.77 & $\sim$ & 1.14 & 1.06 & 0.72 & $\sim$ & 1.06 & 1.25 & 0.76 & $\sim$ & 1.25 \\
\hline 4400 & 1.36 & 1.05 & $\sim$ & 1.36 & 1.22 & 0.93 & $\sim$ & 1.22 & 1.14 & 0.76 & $\sim$ & 1.14 & 1.06 & 0.71 & $\sim$ & 1.06 & 1.24 & 0.76 & $\sim$ & 1.24 \\
\hline 4500 & 1.35 & 1.04 & $\sim$ & 1.35 & 1.21 & 0.92 & $\sim$ & 1.21 & 1.14 & 0.75 & $\sim$ & 1.14 & 1.06 & 0.70 & $\sim$ & 1.06 & 1.24 & 0.75 & $\sim$ & 1.24 \\
\hline 4600 & 1.34 & 1.02 & $\sim$ & 1.34 & 1.20 & 0.91 & $\sim$ & 1.20 & 1.14 & 0.74 & $\sim$ & 1.14 & 1.07 & 0.69 & $\sim$ & 1.07 & 1.23 & 0.74 & $\sim$ & 1.23 \\
\hline 4700 & 1.32 & 1.01 & $\sim$ & 1.32 & 1.20 & 0.90 & $\sim$ & 1.20 & 1.14 & 0.73 & $\sim$ & 1.14 & 1.07 & 0.68 & $\sim$ & 1.07 & 1.23 & 0.73 & $\sim$ & 1.23 \\
\hline 4800 & 1.31 & 1.00 & $\sim$ & 1.31 & 1.19 & 0.89 & $\sim$ & 1.19 & 1.14 & 0.72 & $\sim$ & 1.14 & 1.07 & 0.67 & $\sim$ & 1.07 & 1.22 & 0.73 & $\sim$ & 1.22 \\
\hline 4900 & 1.29 & 0.98 & $\sim$ & 1.29 & 1.18 & 0.87 & $\sim$ & 1.18 & 1.14 & 0.71 & $\sim$ & 1.14 & 1.08 & 0.66 & $\sim$ & 1.08 & 1.22 & 0.72 & $\sim$ & 1.22 \\
\hline 5000 & 1.28 & 0.97 & $\sim$ & 1.28 & 1.18 & 0.86 & $\sim$ & 1.18 & 1.15 & 0.70 & $\sim$ & 1.15 & 1.08 & 0.65 & $\sim$ & 1.08 & 1.21 & 0.71 & $\sim$ & 1.21 \\
\hline 5100 & 1.26 & 0.96 & $\sim$ & 1.26 & 1.17 & 0.85 & $\sim$ & 1.17 & 1.15 & 0.69 & $\sim$ & 1.15 & 1.08 & 0.64 & $\sim$ & 1.08 & 1.21 & 0.70 & $\sim$ & 1.21 \\
\hline 5200 & 1.24 & 0.94 & $\sim$ & 1.24 & 1.16 & 0.84 & $\sim$ & 1.16 & 1.15 & 0.68 & $\sim$ & 1.15 & 1.09 & 0.63 & $\sim$ & 1.09 & 1.20 & 0.69 & $\sim$ & 1.20 \\
\hline 5300 & 1.23 & 0.93 & $\sim$ & 1.23 & 1.16 & 0.82 & $\sim$ & 1.16 & 1.15 & 0.67 & $\sim$ & 1.15 & 1.09 & 0.62 & $\sim$ & 1.09 & 1.20 & 0.69 & $\sim$ & 1.20 \\
\hline 5400 & 1.21 & 0.91 & $\sim$ & 1.21 & 1.15 & 0.81 & $\sim$ & 1.15 & 1.16 & 0.65 & $\sim$ & 1.16 & 1.10 & 0.62 & $\sim$ & 1.10 & 1.19 & 0.68 & $\sim$ & 1.19 \\
\hline 5500 & 1.20 & 0.90 & $\sim$ & 1.20 & 1.14 & 0.80 & $\sim$ & 1.14 & 1.16 & 0.64 & $\sim$ & 1.16 & 1.10 & 0.61 & $\sim$ & 1.10 & 1.19 & 0.67 & $\sim$ & 1.19 \\
\hline 5600 & 1.18 & 0.89 & $\sim$ & 1.18 & 1.14 & 0.79 & $\sim$ & 1.14 & 1.16 & 0.63 & $\sim$ & 1.16 & 1.10 & 0.60 & $\sim$ & 1.10 & 1.18 & 0.66 & $\sim$ & 1.18 \\
\hline 5700 & 1.17 & 0.87 & $\sim$ & 1.17 & 1.13 & 0.77 & $\sim$ & 1.13 & 1.16 & 0.62 & $\sim$ & 1.16 & 1.11 & 0.59 & $\sim$ & 1.11 & 1.18 & 0.65 & $\sim$ & 1.18 \\
\hline 5800 & 1.15 & 0.86 & $\sim$ & 1.15 & 1.12 & 0.76 & $\sim$ & 1.12 & 1.17 & 0.61 & $\sim$ & 1.17 & 1.11 & 0.58 & $\sim$ & 1.11 & 1.17 & 0.64 & $\sim$ & 1.17 \\
\hline 5900 & 1.13 & 0.84 & $\sim$ & 1.13 & 1.12 & 0.75 & $\sim$ & 1.12 & 1.17 & 0.60 & $\sim$ & 1.17 & 1.12 & 0.57 & $\sim$ & 1.12 & 1.17 & 0.63 & $\sim$ & 1.17 \\
\hline 6000 & 1.12 & 0.83 & $\sim$ & 1.12 & 1.11 & 0.74 & $\sim$ & 1.11 & 1.17 & 0.59 & $\sim$ & 1.17 & 1.12 & 0.56 & $\sim$ & 1.12 & 1.16 & 0.62 & $\sim$ & 1.16 \\
\hline 6100 & 1.10 & 0.81 & $\sim$ & 1.10 & 1.10 & 0.72 & $\sim$ & 1.10 & 1.18 & 0.58 & $\sim$ & 1.18 & 1.13 & 0.55 & $\sim$ & 1.13 & 1.16 & 0.62 & $\sim$ & 1.16 \\
\hline 6200 & 1.09 & 0.80 & $\sim$ & 1.09 & 1.10 & 0.71 & $\sim$ & 1.10 & 1.18 & 0.57 & $\sim$ & 1.18 & 1.13 & 0.55 & $\sim$ & 1.13 & 1.15 & 0.61 & $\sim$ & 1.15 \\
\hline 6300 & 1.07 & 0.79 & $\sim$ & 1.07 & 1.09 & 0.70 & $\sim$ & 1.09 & 1.18 & 0.56 & $\sim$ & 1.18 & 1.14 & 0.54 & $\sim$ & 1.14 & 1.15 & 0.60 & $\sim$ & 1.15 \\
\hline 6400 & 1.06 & 0.77 & $\sim$ & 1.06 & 1.08 & 0.69 & $\sim$ & 1.08 & 1.19 & 0.55 & $\sim$ & 1.19 & 1.14 & 0.53 & $\sim$ & 1.14 & 1.15 & 0.59 & $\sim$ & 1.15 \\
\hline 6500 & 1.04 & 0.76 & $\sim$ & 1.04 & 1.08 & 0.68 & $\sim$ & 1.08 & 1.19 & 0.54 & $\sim$ & 1.19 & 1.15 & 0.52 & $\sim$ & 1.15 & 1.14 & 0.58 & $\sim$ & 1.14 \\
\hline 6600 & 1.03 & 0.75 & $\sim$ & 1.03 & 1.07 & 0.66 & $\sim$ & 1.07 & 1.19 & 0.53 & $\sim$ & 1.19 & 1.15 & 0.51 & $\sim$ & 1.15 & 1.14 & 0.57 & $\sim$ & 1.14 \\
\hline 6700 & 1.01 & 0.73 & $\sim$ & 1.01 & 1.06 & 0.65 & $\sim$ & 1.06 & 1.20 & 0.52 & $\sim$ & 1.20 & 1.16 & 0.51 & $\sim$ & 1.16 & 1.14 & 0.56 & $\sim$ & 1.14 \\
\hline 6800 & 1.00 & 0.72 & $\sim$ & 1.00 & 1.06 & 0.64 & $\sim$ & 1.06 & 1.20 & 0.51 & $\sim$ & 1.20 & 1.16 & 0.50 & $\sim$ & 1.16 & 1.13 & 0.55 & $\sim$ & 1.13 \\
\hline 6900 & 0.99 & 0.71 & $\sim$ & 0.99 & 1.05 & 0.63 & $\sim$ & 1.05 & 1.20 & 0.50 & $\sim$ & 1.20 & 1.17 & 0.49 & $\sim$ & 1.17 & 1.13 & 0.55 & $\sim$ & 1.13 \\
\hline 7000 & 0.97 & 0.69 & $\sim$ & 0.97 & 1.05 & 0.62 & $\sim$ & 1.05 & 1.21 & 0.50 & $\sim$ & 1.21 & 1.17 & 0.48 & $\sim$ & 1.17 & 1.13 & 0.54 & $\sim$ & 1.13 \\
\hline 7100 & 0.96 & 0.68 & $\sim$ & 0.96 & 1.04 & 0.61 & $\sim$ & 1.04 & 1.21 & 0.49 & $\sim$ & 1.21 & 1.18 & 0.48 & $\sim$ & 1.18 & 1.12 & 0.53 & $\sim$ & 1.12 \\
\hline 7200 & 0.95 & 0.67 & $\sim$ & 0.95 & 1.03 & 0.60 & $\sim$ & 1.03 & 1.21 & 0.48 & $\sim$ & 1.21 & 1.18 & 0.47 & $\sim$ & 1.18 & 1.12 & 0.52 & $\sim$ & 1.12 \\
\hline 7300 & 0.93 & 0.66 & $\sim$ & 0.93 & 1.03 & 0.59 & $\sim$ & 1.03 & 1.22 & 0.47 & $\sim$ & 1.22 & 1.18 & 0.46 & $\sim$ & 1.18 & 1.12 & 0.51 & $\sim$ & 1.12 \\
\hline 7400 & 0.92 & 0.65 & $\sim$ & 0.92 & 1.02 & 0.58 & $\sim$ & 1.02 & 1.22 & 0.46 & $\sim$ & 1.22 & 1.19 & 0.46 & $\sim$ & 1.19 & 1.12 & 0.51 & $\sim$ & 1.12 \\
\hline 7500 & 0.91 & 0.63 & $\sim$ & 0.91 & 1.01 & 0.57 & $\sim$ & 1.01 & 1.22 & 0.45 & $\sim$ & 1.22 & 1.19 & 0.45 & $\sim$ & 1.19 & 1.11 & 0.50 & $\sim$ & 1.11 \\
\hline 7600 & 0.90 & 0.62 & $\sim$ & 0.90 & 1.01 & 0.56 & $\sim$ & 1.01 & 1.23 & 0.45 & $\sim$ & 1.23 & 1.20 & 0.44 & $\sim$ & 1.20 & 1.11 & 0.49 & $\sim$ & 1.11 \\
\hline 7700 & 0.88 & 0.61 & $\sim$ & 0.88 & 1.00 & 0.55 & $\sim$ & 1.00 & 1.23 & 0.44 & $\sim$ & 1.23 & 1.20 & 0.44 & $\sim$ & 1.20 & 1.11 & 0.48 & $\sim$ & 1.11 \\
\hline
\end{tabular}




\begin{tabular}{|c|c|c|c|c|c|c|c|c|c|c|c|c|c|c|c|c|c|c|c|c|}
\hline 7800 & 0.87 & 0.60 & $\sim$ & 0.87 & 1.00 & 0.54 & $\sim$ & 1.00 & 1.23 & 0.43 & $\sim$ & 1.23 & 1.21 & 0.43 & $\sim$ & 1.21 & 1.11 & 0.48 & $\sim$ & 1.11 \\
\hline 7900 & 0.86 & 0.59 & $\sim$ & 0.86 & 0.99 & 0.53 & $\sim$ & 0.99 & 1.23 & 0.43 & $\sim$ & 1.23 & 1.21 & 0.43 & $\sim$ & 1.21 & 1.10 & 0.47 & $\sim$ & 1.10 \\
\hline 8000 & 0.85 & 0.58 & $\sim$ & 0.85 & 0.99 & 0.52 & $\sim$ & 0.99 & 1.24 & 0.42 & $\sim$ & 1.24 & 1.21 & 0.42 & $\sim$ & 1.21 & 1.10 & 0.46 & $\sim$ & 1.10 \\
\hline 8100 & 0.84 & 0.57 & $\sim$ & 0.84 & 0.98 & 0.51 & $\sim$ & 0.98 & 1.24 & 0.41 & $\sim$ & 1.24 & 1.22 & 0.42 & $\sim$ & 1.22 & 1.10 & 0.46 & $\sim$ & 1.10 \\
\hline 8200 & 0.83 & 0.56 & $\sim$ & 0.83 & 0.97 & 0.51 & $\sim$ & 0.97 & 1.24 & 0.41 & $\sim$ & 1.24 & 1.22 & 0.41 & $\sim$ & 1.22 & 1.10 & 0.45 & $\sim$ & 1.10 \\
\hline 8300 & 0.82 & 0.55 & $\sim$ & 0.82 & 0.97 & 0.50 & $\sim$ & 0.97 & 1.24 & 0.40 & $\sim$ & 1.24 & 1.22 & 0.41 & $\sim$ & 1.22 & 1.10 & 0.45 & $\sim$ & 1.10 \\
\hline 8400 & 0.81 & 0.54 & $\sim$ & 0.81 & 0.96 & 0.49 & $\sim$ & 0.96 & 1.24 & 0.40 & $\sim$ & 1.24 & 1.23 & 0.40 & $\sim$ & 1.23 & 1.10 & 0.44 & $\sim$ & 1.10 \\
\hline 8500 & 0.80 & 0.54 & $\sim$ & 0.80 & 0.96 & 0.48 & $\sim$ & 0.96 & 1.25 & 0.39 & $\sim$ & 1.25 & 1.23 & 0.40 & $\sim$ & 1.23 & 1.09 & 0.43 & $\sim$ & 1.09 \\
\hline 8600 & 0.79 & 0.53 & $\sim$ & 0.79 & 0.95 & 0.48 & $\sim$ & 0.95 & 1.25 & 0.38 & $\sim$ & 1.25 & 1.23 & 0.40 & $\sim$ & 1.23 & 1.09 & 0.43 & $\sim$ & 1.09 \\
\hline 8700 & 0.78 & 0.52 & $\sim$ & 0.78 & 0.95 & 0.47 & $\sim$ & 0.95 & 1.25 & 0.38 & $\sim$ & 1.25 & 1.23 & 0.39 & $\sim$ & 1.23 & 1.09 & 0.42 & $\sim$ & 1.09 \\
\hline 8800 & 0.77 & 0.51 & $\sim$ & 0.77 & 0.94 & 0.46 & $\sim$ & 0.94 & 1.25 & 0.38 & $\sim$ & 1.25 & 1.24 & 0.39 & $\sim$ & 1.24 & 1.09 & 0.42 & $\sim$ & 1.09 \\
\hline 8900 & 0.76 & 0.50 & $\sim$ & 0.76 & 0.94 & 0.46 & $\sim$ & 0.94 & 1.25 & 0.37 & $\sim$ & 1.25 & 1.24 & 0.38 & $\sim$ & 1.24 & 1.09 & 0.41 & $\sim$ & 1.09 \\
\hline 9000 & 0.76 & 0.50 & $\sim$ & 0.76 & 0.93 & 0.45 & $\sim$ & 0.93 & 1.25 & 0.37 & $\sim$ & 1.25 & 1.24 & 0.38 & $\sim$ & 1.24 & 1.09 & 0.41 & $\sim$ & 1.09 \\
\hline 9100 & 0.75 & 0.49 & $\sim$ & 0.75 & 0.93 & 0.45 & $\sim$ & 0.93 & 1.25 & 0.36 & $\sim$ & 1.25 & 1.24 & 0.38 & $\sim$ & 1.24 & 1.09 & 0.40 & $\sim$ & 1.09 \\
\hline 9200 & 0.74 & 0.48 & $\sim$ & 0.74 & 0.92 & 0.44 & $\sim$ & 0.92 & 1.25 & 0.36 & $\sim$ & 1.25 & 1.24 & 0.38 & $\sim$ & 1.24 & 1.09 & 0.40 & $\sim$ & 1.09 \\
\hline 9300 & 0.73 & 0.48 & $\sim$ & 0.73 & 0.92 & 0.43 & $\sim$ & 0.92 & 1.25 & 0.35 & $\sim$ & 1.25 & 1.24 & 0.37 & $\sim$ & 1.24 & 1.08 & 0.40 & $\sim$ & 1.08 \\
\hline 9400 & 0.73 & 0.47 & $\sim$ & 0.73 & 0.91 & 0.43 & $\sim$ & 0.91 & 1.25 & 0.35 & $\sim$ & 1.25 & 1.24 & 0.37 & $\sim$ & 1.24 & 1.08 & 0.39 & $\sim$ & 1.08 \\
\hline 9500 & 0.72 & 0.47 & $\sim$ & 0.72 & 0.91 & 0.42 & $\sim$ & 0.91 & 1.25 & 0.35 & $\sim$ & 1.25 & 1.24 & 0.37 & $\sim$ & 1.24 & 1.08 & 0.39 & $\sim$ & 1.08 \\
\hline 9600 & 0.71 & 0.46 & $\sim$ & 0.71 & 0.90 & 0.42 & $\sim$ & 0.90 & 1.25 & 0.35 & $\sim$ & 1.25 & 1.24 & 0.37 & $\sim$ & 1.24 & 1.08 & 0.38 & $\sim$ & 1.08 \\
\hline 9700 & 0.71 & 0.46 & $\sim$ & 0.71 & 0.90 & 0.42 & $\sim$ & 0.90 & 1.25 & 0.34 & $\sim$ & 1.25 & 1.24 & 0.36 & $\sim$ & 1.24 & 1.08 & 0.38 & $\sim$ & 1.08 \\
\hline 9800 & 0.70 & 0.45 & $\sim$ & 0.70 & 0.89 & 0.41 & $\sim$ & 0.89 & 1.25 & 0.34 & $\sim$ & 1.25 & 1.24 & 0.36 & $\sim$ & 1.24 & 1.08 & 0.38 & $\sim$ & 1.08 \\
\hline 9900 & 0.70 & 0.45 & $\sim$ & 0.70 & 0.89 & 0.41 & $\sim$ & 0.89 & 1.24 & 0.34 & $\sim$ & 1.24 & 1.24 & 0.36 & $\sim$ & 1.24 & 1.08 & 0.38 & $\sim$ & 1.08 \\
\hline 10000 & 0.69 & 0.44 & $\sim$ & 0.69 & 0.89 & 0.41 & $\sim$ & 0.89 & 1.24 & 0.34 & $\sim$ & 1.24 & 1.24 & 0.36 & $\sim$ & 1.24 & 1.08 & 0.37 & $\sim$ & 1.08 \\
\hline 10100 & 0.69 & 0.44 & $\sim$ & 0.69 & 0.88 & 0.40 & $\sim$ & 0.88 & 1.24 & 0.33 & $\sim$ & 1.24 & 1.24 & 0.36 & $\sim$ & 1.24 & 1.08 & 0.37 & $\sim$ & 1.08 \\
\hline 10200 & 0.68 & 0.44 & $\sim$ & 0.68 & 0.88 & 0.40 & $\sim$ & 0.88 & 1.24 & 0.33 & $\sim$ & 1.24 & 1.24 & 0.36 & $\sim$ & 1.24 & 1.08 & 0.37 & $\sim$ & 1.08 \\
\hline 10300 & 0.68 & 0.43 & $\sim$ & 0.68 & 0.87 & 0.40 & $\sim$ & 0.87 & 1.23 & 0.33 & $\sim$ & 1.23 & 1.23 & 0.36 & $\sim$ & 1.23 & 1.08 & 0.37 & $\sim$ & 1.08 \\
\hline 10400 & 0.67 & 0.43 & $\sim$ & 0.67 & 0.87 & 0.40 & $\sim$ & 0.87 & 1.23 & 0.33 & $\sim$ & 1.23 & 1.23 & 0.36 & $\sim$ & 1.23 & 1.08 & 0.37 & $\sim$ & 1.08 \\
\hline 10500 & 0.67 & 0.43 & $\sim$ & 0.67 & 0.87 & 0.39 & $\sim$ & 0.87 & 1.23 & 0.33 & $\sim$ & 1.23 & 1.23 & 0.36 & $\sim$ & 1.23 & 1.08 & 0.37 & $\sim$ & 1.08 \\
\hline 10600 & 0.67 & 0.43 & $\sim$ & 0.67 & 0.86 & 0.39 & $\sim$ & 0.86 & 1.22 & 0.33 & $\sim$ & 1.22 & 1.22 & 0.36 & $\sim$ & 1.22 & 1.08 & 0.36 & $\sim$ & 1.08 \\
\hline 10700 & 0.66 & 0.43 & $\sim$ & 0.66 & 0.86 & 0.39 & $\sim$ & 0.86 & 1.22 & 0.33 & $\sim$ & 1.22 & 1.22 & 0.36 & $\sim$ & 1.22 & 1.08 & 0.36 & $\sim$ & 1.08 \\
\hline 10800 & 0.66 & 0.42 & $\sim$ & 0.66 & 0.86 & 0.39 & $\sim$ & 0.86 & 1.21 & 0.33 & $\sim$ & 1.21 & 1.21 & 0.36 & $\sim$ & 1.21 & 1.08 & 0.36 & $\sim$ & 1.08 \\
\hline 10900 & 0.66 & 0.42 & $\sim$ & 0.66 & 0.85 & 0.39 & $\sim$ & 0.85 & 1.21 & 0.33 & $\sim$ & 1.21 & 1.21 & 0.36 & $\sim$ & 1.21 & 1.08 & 0.36 & $\sim$ & 1.08 \\
\hline 11000 & 0.66 & 0.42 & $\sim$ & 0.66 & 0.85 & 0.39 & $\sim$ & 0.85 & 1.20 & 0.33 & $\sim$ & 1.20 & 1.20 & 0.36 & $\sim$ & 1.20 & 1.08 & 0.36 & $\sim$ & 1.08 \\
\hline 11100 & 0.65 & 0.42 & $\sim$ & 0.65 & 0.85 & 0.39 & $\sim$ & 0.85 & 1.20 & 0.33 & $\sim$ & 1.20 & 1.20 & 0.36 & $\sim$ & 1.20 & 1.08 & 0.36 & $\sim$ & 1.08 \\
\hline 11200 & 0.65 & 0.42 & $\sim$ & 0.65 & 0.85 & 0.39 & $\sim$ & 0.85 & 1.19 & 0.33 & $\sim$ & 1.19 & 1.19 & 0.37 & $\sim$ & 1.19 & 1.08 & 0.36 & $\sim$ & 1.08 \\
\hline 11300 & 0.65 & 0.42 & $\sim$ & 0.65 & 0.84 & 0.39 & $\sim$ & 0.84 & 1.18 & 0.33 & $\sim$ & 1.18 & 1.19 & 0.37 & $\sim$ & 1.19 & 1.08 & 0.37 & $\sim$ & 1.08 \\
\hline 11400 & 0.65 & 0.42 & $\sim$ & 0.65 & 0.84 & 0.39 & $\sim$ & 0.84 & 1.18 & 0.33 & $\sim$ & 1.18 & 1.18 & 0.37 & $\sim$ & 1.18 & 1.08 & 0.37 & $\sim$ & 1.08 \\
\hline 11500 & 0.65 & 0.43 & $\sim$ & 0.65 & 0.84 & 0.39 & $\sim$ & 0.84 & 1.17 & 0.34 & $\sim$ & 1.17 & 1.17 & 0.37 & $\sim$ & 1.17 & 1.08 & 0.37 & $\sim$ & 1.08 \\
\hline 11600 & 0.65 & 0.43 & $\sim$ & 0.65 & 0.84 & 0.39 & $\sim$ & 0.84 & 1.16 & 0.34 & $\sim$ & 1.16 & 1.16 & 0.38 & $\sim$ & 1.16 & 1.08 & 0.37 & $\sim$ & 1.08 \\
\hline 11700 & 0.65 & 0.43 & $\sim$ & 0.65 & 0.84 & 0.39 & $\sim$ & 0.84 & 1.15 & 0.34 & $\sim$ & 1.15 & 1.15 & 0.38 & $\sim$ & 1.15 & 1.08 & 0.37 & $\sim$ & 1.08 \\
\hline 11800 & 0.65 & 0.43 & $\sim$ & 0.65 & 0.83 & 0.40 & $\sim$ & 0.83 & 1.15 & 0.34 & $\sim$ & 1.15 & 1.15 & 0.38 & $\sim$ & 1.15 & 1.08 & 0.37 & $\sim$ & 1.08 \\
\hline 11900 & 0.66 & 0.44 & $\sim$ & 0.66 & 0.83 & 0.40 & $\sim$ & 0.83 & 1.14 & 0.35 & $\sim$ & 1.14 & 1.14 & 0.39 & $\sim$ & 1.14 & 1.09 & 0.38 & $\sim$ & 1.09 \\
\hline 12000 & 0.66 & 0.44 & $\sim$ & 0.66 & 0.83 & 0.40 & $\sim$ & 0.83 & 1.13 & 0.35 & $\sim$ & 1.13 & 1.13 & 0.39 & $\sim$ & 1.13 & 1.09 & 0.38 & $\sim$ & 1.09 \\
\hline 12100 & 0.66 & 0.44 & $\sim$ & 0.66 & 0.83 & 0.40 & $\sim$ & 0.83 & 1.12 & 0.35 & $\sim$ & 1.12 & 1.12 & 0.40 & $\sim$ & 1.12 & 1.09 & 0.38 & $\sim$ & 1.09 \\
\hline 12200 & 0.66 & 0.45 & $\sim$ & 0.66 & 0.83 & 0.41 & $\sim$ & 0.83 & 1.11 & 0.36 & $\sim$ & 1.11 & 1.11 & 0.40 & $\sim$ & 1.11 & 1.09 & 0.39 & $\sim$ & 1.09 \\
\hline 12300 & 0.67 & 0.45 & $\sim$ & 0.67 & 0.83 & 0.41 & $\sim$ & 0.83 & 1.10 & 0.36 & $\sim$ & 1.10 & 1.10 & 0.41 & $\sim$ & 1.10 & 1.09 & 0.39 & $\sim$ & 1.09 \\
\hline 12400 & 0.67 & 0.46 & $\sim$ & 0.67 & 0.83 & 0.42 & $\sim$ & 0.83 & 1.09 & 0.37 & $\sim$ & 1.09 & 1.09 & 0.42 & $\sim$ & 1.09 & 1.09 & 0.40 & $\sim$ & 1.09 \\
\hline 12500 & 0.68 & 0.46 & $\sim$ & 0.68 & 0.83 & 0.42 & $\sim$ & 0.83 & 1.08 & 0.38 & $\sim$ & 1.08 & 1.08 & 0.42 & $\sim$ & 1.08 & 1.10 & 0.40 & $\sim$ & 1.10 \\
\hline 12600 & 0.68 & 0.47 & $\sim$ & 0.68 & 0.83 & 0.43 & $\sim$ & 0.83 & 1.07 & 0.38 & $\sim$ & 1.07 & 1.07 & 0.43 & $\sim$ & 1.07 & 1.10 & 0.41 & $\sim$ & 1.10 \\
\hline 12700 & 0.69 & 0.48 & $\sim$ & 0.69 & 0.83 & 0.43 & $\sim$ & 0.83 & 1.06 & 0.39 & $\sim$ & 1.06 & 1.05 & 0.44 & $\sim$ & 1.05 & 1.10 & 0.41 & $\sim$ & 1.10 \\
\hline 12800 & 0.69 & 0.49 & $\sim$ & 0.69 & 0.83 & 0.44 & $\sim$ & 0.83 & 1.05 & 0.40 & $\sim$ & 1.05 & 1.04 & 0.45 & $\sim$ & 1.04 & 1.10 & 0.42 & $\sim$ & 1.10 \\
\hline 12900 & 0.70 & 0.49 & $\sim$ & 0.70 & 0.83 & 0.45 & $\sim$ & 0.83 & 1.04 & 0.40 & $\sim$ & 1.04 & 1.03 & 0.45 & $\sim$ & 1.03 & 1.11 & 0.43 & $\sim$ & 1.11 \\
\hline 13000 & 0.71 & 0.50 & $\sim$ & 0.71 & 0.83 & 0.46 & $\sim$ & 0.83 & 1.03 & 0.41 & $\sim$ & 1.03 & 1.02 & 0.46 & $\sim$ & 1.02 & 1.11 & 0.44 & $\sim$ & 1.11 \\
\hline 13100 & 0.72 & 0.51 & $\sim$ & 0.72 & 0.83 & 0.46 & $\sim$ & 0.83 & 1.01 & 0.42 & $\sim$ & 1.01 & 1.01 & 0.47 & $\sim$ & 1.01 & 1.11 & 0.44 & $\sim$ & 1.11 \\
\hline 13200 & 0.73 & 0.52 & $\sim$ & 0.73 & 0.83 & 0.47 & $\sim$ & 0.83 & 1.00 & 0.43 & $\sim$ & 1.00 & 1.00 & 0.48 & $\sim$ & 1.00 & 1.12 & 0.45 & $\sim$ & 1.12 \\
\hline 13300 & 0.74 & 0.53 & $\sim$ & 0.74 & 0.84 & 0.48 & $\sim$ & 0.84 & 0.99 & 0.44 & $\sim$ & 0.99 & 0.98 & 0.50 & $\sim$ & 0.98 & 1.12 & 0.46 & $\sim$ & 1.12 \\
\hline 13400 & 0.75 & 0.55 & $\sim$ & 0.75 & 0.84 & 0.49 & $\sim$ & 0.84 & 0.98 & 0.45 & $\sim$ & 0.98 & 0.97 & 0.51 & $\sim$ & 0.97 & 1.13 & 0.47 & $\sim$ & 1.13 \\
\hline 13500 & 0.76 & 0.56 & $\sim$ & 0.76 & 0.84 & 0.50 & $\sim$ & 0.84 & 0.97 & 0.46 & $\sim$ & 0.97 & 0.96 & 0.52 & $\sim$ & 0.96 & 1.13 & 0.48 & $\sim$ & 1.13 \\
\hline 13600 & 0.78 & 0.57 & $\sim$ & 0.78 & 0.85 & 0.51 & $\sim$ & 0.85 & 0.96 & 0.48 & $\sim$ & 0.96 & 0.95 & 0.53 & $\sim$ & 0.95 & 1.14 & 0.49 & $\sim$ & 1.14 \\
\hline 13700 & 0.79 & 0.59 & $\sim$ & 0.79 & 0.85 & 0.53 & $\sim$ & 0.85 & 0.94 & 0.49 & $\sim$ & 0.94 & 0.94 & 0.55 & $\sim$ & 0.94 & 1.15 & 0.51 & $\sim$ & 1.15 \\
\hline 13800 & 0.81 & 0.60 & $\sim$ & 0.81 & 0.85 & 0.54 & $\sim$ & 0.85 & 0.93 & 0.50 & $\sim$ & 0.93 & 0.93 & 0.56 & $\sim$ & 0.93 & 1.16 & 0.52 & $\sim$ & 1.16 \\
\hline 13900 & 0.83 & 0.62 & $\sim$ & 0.83 & 0.86 & 0.55 & $\sim$ & 0.86 & 0.92 & 0.52 & $\sim$ & 0.92 & 0.92 & 0.57 & $\sim$ & 0.92 & 1.17 & 0.53 & $\sim$ & 1.17 \\
\hline 14000 & 0.85 & 0.63 & $\sim$ & 0.85 & 0.87 & 0.57 & $\sim$ & 0.87 & 0.91 & 0.53 & $\sim$ & 0.91 & 0.91 & 0.58 & $\sim$ & 0.91 & 1.18 & 0.54 & $\sim$ & 1.18 \\
\hline 14100 & 0.88 & 0.65 & $\sim$ & 0.88 & 0.87 & 0.58 & $\sim$ & 0.87 & 0.90 & 0.55 & $\sim$ & 0.90 & 0.91 & 0.60 & $\sim$ & 0.91 & 1.19 & 0.56 & $\sim$ & 1.19 \\
\hline 14200 & 0.90 & 0.67 & $\sim$ & 0.90 & 0.88 & 0.60 & $\sim$ & 0.88 & 0.90 & 0.57 & $\sim$ & 0.90 & 0.91 & 0.61 & $\sim$ & 0.91 & 1.20 & 0.57 & $\sim$ & 1.20 \\
\hline 14300 & 0.93 & 0.69 & $\sim$ & 0.93 & 0.89 & 0.62 & $\sim$ & 0.89 & 0.89 & 0.58 & $\sim$ & 0.89 & 0.91 & 0.62 & $\sim$ & 0.91 & 1.22 & 0.59 & $\sim$ & 1.22 \\
\hline 14400 & 0.96 & 0.71 & $\sim$ & 0.96 & 0.90 & 0.63 & $\sim$ & 0.90 & 0.89 & 0.60 & $\sim$ & 0.89 & 0.91 & 0.62 & $\sim$ & 0.91 & 1.23 & 0.60 & $\sim$ & 1.23 \\
\hline 14500 & 0.99 & 0.73 & $\sim$ & 0.99 & 0.91 & 0.65 & $\sim$ & 0.91 & 0.89 & 0.61 & $\sim$ & 0.89 & 0.92 & 0.63 & $\sim$ & 0.92 & 1.25 & 0.62 & $\sim$ & 1.25 \\
\hline 14600 & 1.03 & 0.75 & $\sim$ & 1.03 & 0.93 & 0.67 & $\sim$ & 0.93 & 0.90 & 0.62 & $\sim$ & 0.90 & 0.94 & 0.63 & $\sim$ & 0.94 & 1.27 & 0.63 & $\sim$ & 1.27 \\
\hline 14700 & 1.07 & 0.78 & $\sim$ & 1.07 & 0.95 & 0.69 & $\sim$ & 0.95 & 0.91 & 0.63 & $\sim$ & 0.91 & 0.96 & 0.63 & $\sim$ & 0.96 & 1.30 & 0.65 & $\sim$ & 1.30 \\
\hline 14800 & 1.12 & 0.80 & $\sim$ & 1.12 & 0.97 & 0.70 & $\sim$ & 0.97 & 0.93 & 0.63 & $\sim$ & 0.93 & 0.99 & 0.62 & $\sim$ & 0.99 & 1.33 & 0.66 & $\sim$ & 1.33 \\
\hline 14900 & 1.17 & 0.82 & $\sim$ & 1.17 & 1.00 & 0.72 & $\sim$ & 1.00 & 0.95 & 0.63 & $\sim$ & 0.95 & 1.02 & 0.61 & $\sim$ & 1.02 & 1.36 & 0.68 & $\sim$ & 1.36 \\
\hline 15000 & 1.23 & 0.85 & $\sim$ & 1.23 & 1.02 & 0.73 & $\sim$ & 1.02 & 0.98 & 0.63 & $\sim$ & 0.98 & 1.06 & 0.60 & $\sim$ & 1.06 & 1.40 & 0.69 & $\sim$ & 1.40 \\
\hline 15100 & 1.29 & 0.88 & $\sim$ & 1.29 & 1.06 & 0.75 & $\sim$ & 1.06 & 1.02 & 0.62 & $\sim$ & 1.02 & 1.10 & 0.59 & $\sim$ & 1.10 & 1.44 & 0.71 & $\sim$ & 1.44 \\
\hline
\end{tabular}




\section{Figures}

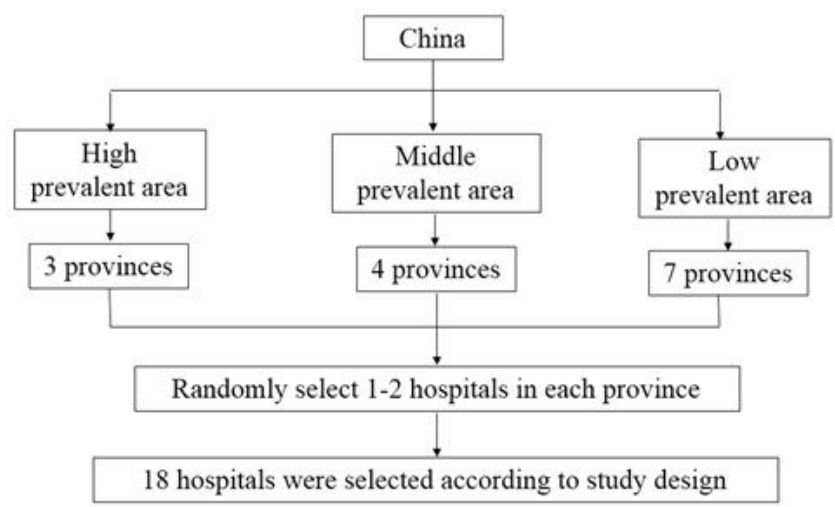

Figure 1

Flow chart of the survey sampling process.

The monthly number of newly confirmed COVID-19 cases

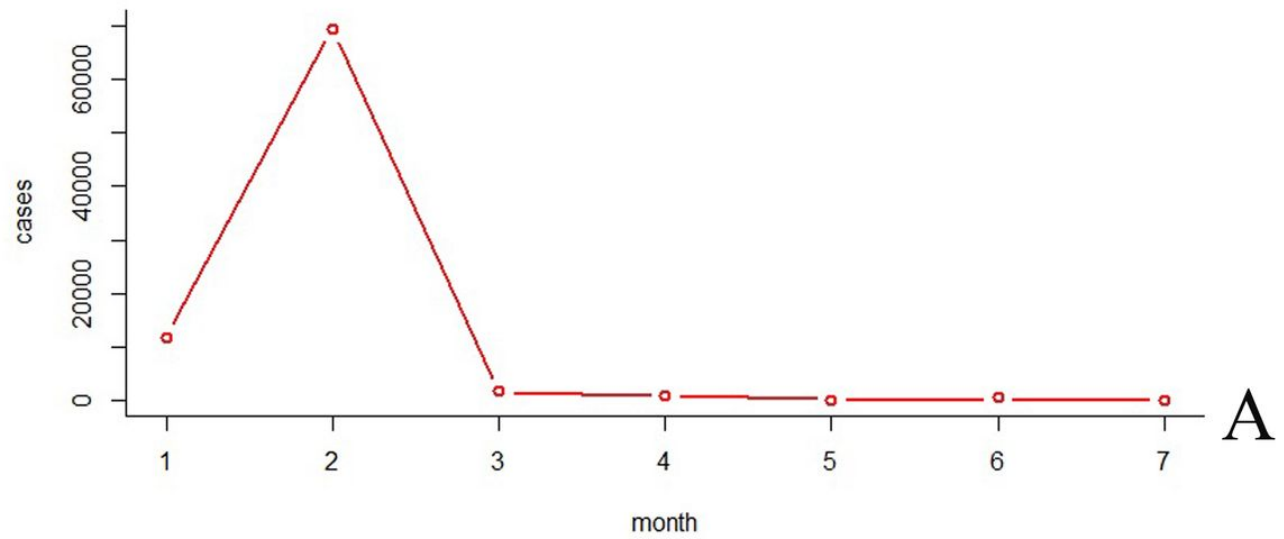

The monthly number of fracture cases during the outbreak of COVID-19

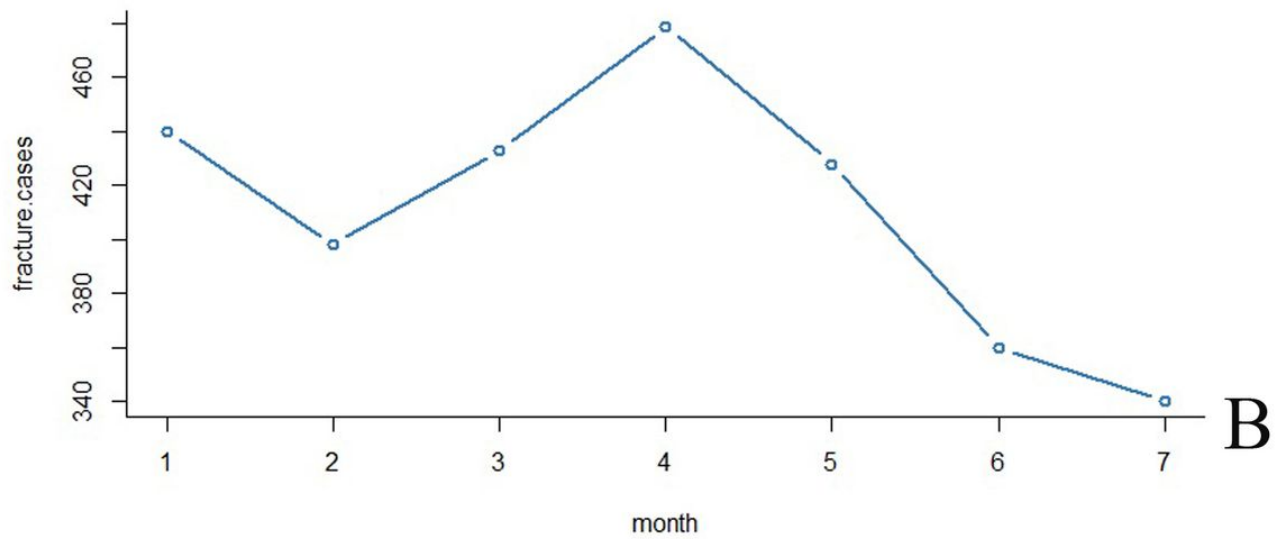

Figure 2

The monthly number of newly confirmed COVID-19 cases and fracture cases 


\section{Number of traumatic fracture cases by age and sex among COVID-19 prevalence in China}

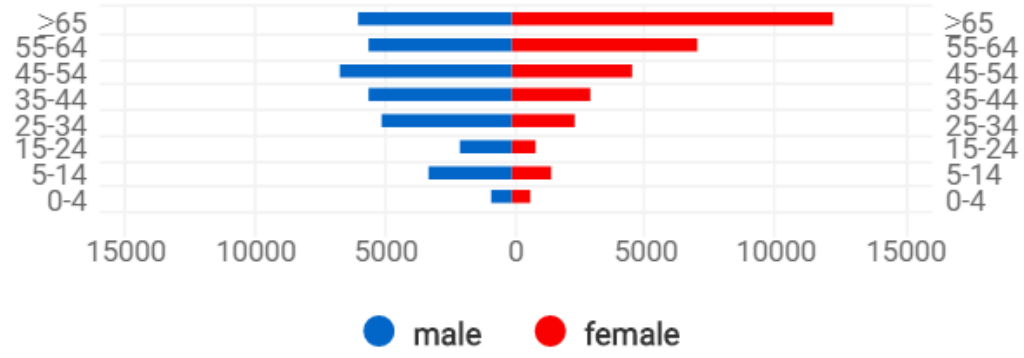

Figure 3

Number of traumatic fracture cases by age and sex among COVID-19 prevalence in China

Age composition in low prevalent area

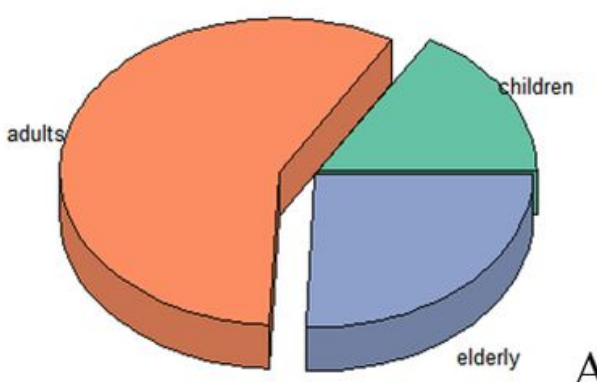

A

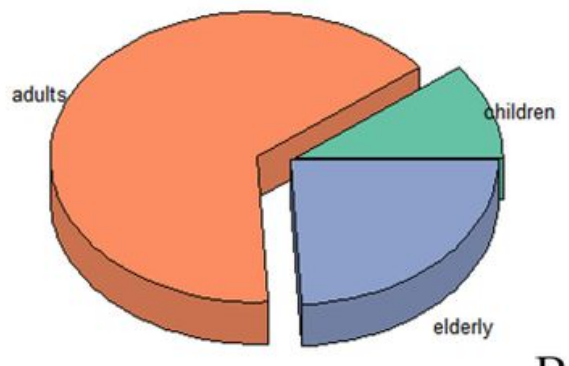

B
Age composition in high prevalent area Age composition in middle prevalent area

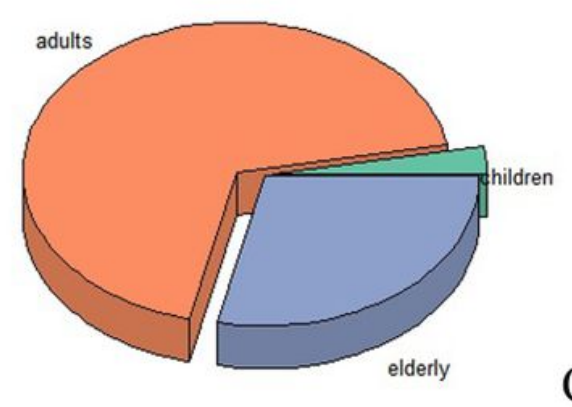

Figure 4

Age composition of traumatic fracture in different prevalent area among COVID-19 prevalence in China

\section{Fracture.location composition}

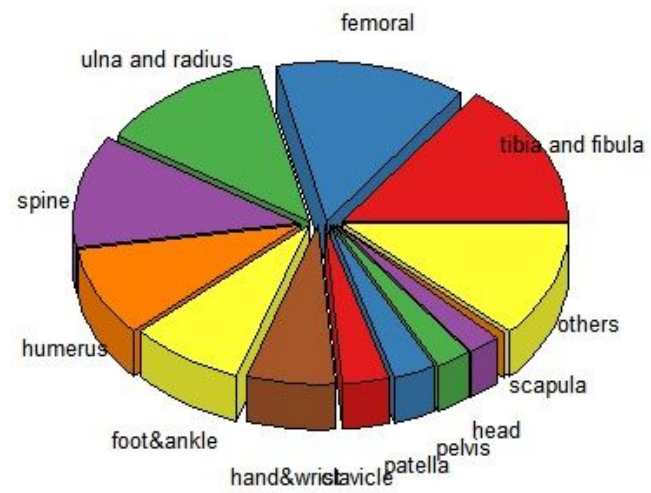

Figure 5

Fracture location composition of COVID-19 prevalence in China 


\section{Injury.mechanism composition}

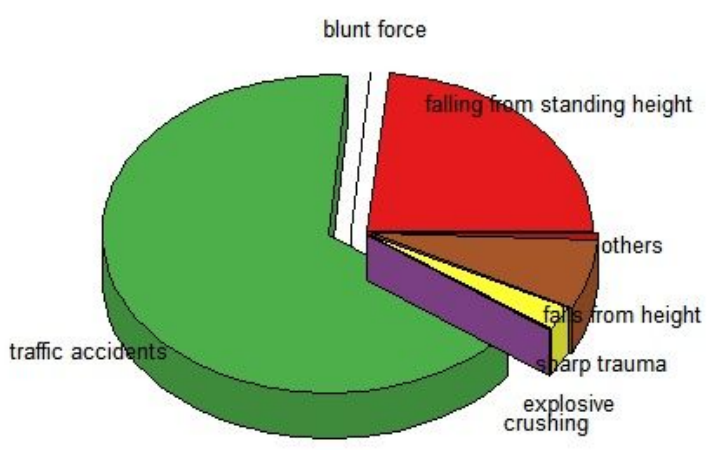

Figure 6

Injury mechanism composition of COVID-19 prevalence in China
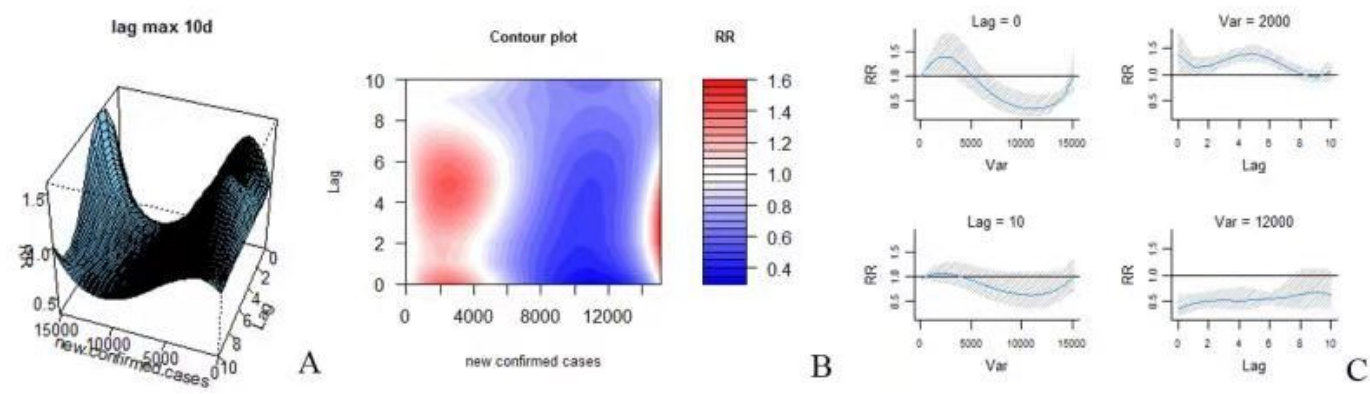

Figure 7

Relationship between new confirmed COVID-19 and fracture risk in China, (A) all fractures in three-dimensional graphs, (B) two-dimensional contour plots, (C) and two-dimensional graphs on different day of lag and new confirmed COVID-19 cases.

\section{Supplementary Files}

This is a list of supplementary files associated with this preprint. Click to download.

- Suppementalfigure1.jpg 